\title{
Zeta potential: a surface electrical characteristic to probe the interaction of nanoparticles with normal and cancer human breast epithelial cells
}

\author{
Yu Zhang • Mo Yang • Nathaniel G. Portney • \\ Daxiang Cui • Gurer Budak • Ekmel Ozbay • \\ Mihrimah Ozkan • Cengiz S. Ozkan
}

Published online: 29 December 2007

(C) Springer Science + Business Media, LLC 2007

\begin{abstract}
We demonstrate the use of surface Zeta potential measurements as a new tool to investigate the interactions of iron oxide nanoparticles and cowpea mosaic virus (CPMV) nanoparticles with human normal breast epithelial cells (MCF10A) and cancer breast epithelial cells (MCF7) respectively. A substantial understanding in the interaction of nanoparticles with normal and cancer cells in vitro will enable the capabilities of improving diagnostic and treatment methods in cancer research, such as imaging and targeted drug delivery. A theoretical Zeta potential model is first established to show the effects of binding process and
\end{abstract}

Y. Zhang $\cdot$ C. S. Ozkan $(\bowtie)$

Department of Mechanical Engineering,

University of California at Riverside,

Riverside, CA 92521, USA

e-mail: cozkan@engr.ucr.edu

Y. Zhang

e-mail: yzhang@engr.ucr.edu

M. Yang

Department of Health Technology and Informatics,

Hong Kong Polytechnic University,

Kowloon, Hong Kong, China

e-mail: Mo.Yang@inet.polyu.edu.hk

N. G. Portney

Department of Bioengineering,

University of California at Riverside,

Riverside, CA 92521, USA

e-mail: nportney@engr.ucr.edu

D. Cui

Department of Bio-Nano Science \& Engineering,

Shanghai JiaoTong University,

Huashan Road 1954,

Shanghai 200030, China

e-mail: dxcui@sjtu.edu.cn internalization process during the nanoparticle uptake by cells and the possible trends of Zeta potential change is predicted for different cell endocytosis capacities. The corresponding changes of total surface charge of cells in the form of Zeta potential measurements were then reported after incubated respectively with iron oxide nanoparticles and CPMV nanoparticles. As observed, after MCF7 and MCF10A cells were incubated respectively with two types of nanoparticles, the significant differences in their surface charge change indicate the potential role of Zeta potential as a valuable biological signature in studying the cellular

G. Budak

Gurer Budak Faculty of Medicine,

Nanomedicine Research Laboratory, Gazi University,

Besevler,

Ankara 06510, Turkey

e-mail: gurer.budak@gazi.edu.tr

E. Ozbay

Nanotechnology Research Center,

Department of Physics and Department of Electrical Engineering,

Bilkent University,

Ankara, Turkey

e-mail: ozbay@bilkent.edu.tr

M. Ozkan

Department of Electrical Engineering,

University of California at Riverside,

Riverside, CA 92521, USA

e-mail: mihri@ee.ucr.edu 
interaction of nanoparticles, as well as specific cell functionality.

Keywords Zeta potential $\cdot$ Normal breast cells $\cdot$ Cancer breast cells · Surface charge · Iron oxide nanoparticles . CPMV nanoparticles $\cdot$ Cell endocytosis

\section{Introduction}

Zeta potential measurements provide an important criterion for the stability of a colloid system (Hunter 1981). In cell biology, the concept of Zeta potential has been used to study cell biological activation, cell agglutination and cell adhesion which are related to cell surface charge properties (Veronesi et al. 2002; Fontes et al. 2006; Lin et al. 2006). In particular, Altankov et al. stated that the Zeta potential might be a critical parameter for cellular interaction (Altankov et al. 2003). Although Zeta potential measurements have been utilized in probing the interaction between cells and biomolecules, it still remains an untapped method for studying the interaction between nanoparticles and biological cells. In this study, we use Zeta potential measurements to probe the surface charge responses of normal breast epithelial cells (MCF10A) and cancer breast epithelial cells (MCF7) during iron oxide nanoparticle and CPMV nanoparticle endocytosis respectively.

Iron oxide and CPMV nanoparticles are the commonly investigated nanoparticles for current cancer therapeutics and diagnosis. Magnetic nanoparticles, especially iron oxide nanoparticles including magnetite $\mathrm{Fe}_{3} \mathrm{O}_{4}$ and maghemite $\left(\gamma-\mathrm{Fe}_{2} \mathrm{O}_{3}\right)$ have been widely studied for their potential applications in a variety of biomedical fields for their unique physical, chemical and magnetic properties (Gupta and Gupta 2005; Berry and Curtis 2003). They are nontoxic, biocompatible (Perez et al. 2002; Dyal et al. 2003) and have been widely used in magnetic resonance imaging (MRI) contrast agents (Lee et al. 2006; Babes et al. 1999), hyperthermia therapy (Hergt et al. 1998; Pardoe et al. 2003; Sonvico et al. 2005) and targeted drug delivery (Gupta and Wells 2004; Alexiou et al. 2000; Jain et al. 2005). Cowpea mosaic virus (CPMV) is one of the smallest plant viruses, which is an icosahedron with a spherical average diameter of $28.4 \mathrm{~nm}$ that built from 60 copies of two asymmetric protein units assembled around a single-stranded bipartite RNA genome (Lewis et al. 2006; Blum et al. 2004). Its highly organized nanoblock structure, chemically addressable sites on the protein shell (the capsid) surface, and $\mathrm{pH}$ and thermally stability over a wide range of conditions make CPMV an excellent choice in biomedical applications including vaccines, vascular imaging, and targeted drug delivery (Lewis et al. 2006; Koudelka et al. 2007; Manchester et al. 2006; Lomonossoff et al. 1999).
Cellular interaction of nanoparticles is one of the big interests in their current biomedical applications. In our study, we observed the distinct changes in Zeta potential measurements of normal breast epithelial cells (MCF10A) and cancer breast epithelial cells (MCF7) after incubated with iron oxide nanopaticles and CPMV nanoparticles respectively. Those changes in Zeta potential values are relative to cell surface charge, nanoparticle surface charge and the interaction between cells and nanoparticles. Our results suggest that Zeta potential is a feasible tool for probing the biological signature in describing the interaction between cells and nanoparticles.

\section{Materials and methods}

\subsection{Cell culture and sample preparation}

MCF7 cancer breast epithelial cells and MCF10A normal breast epithelial cells were purchased from American Type Culture Collection (ATCC). MCF10A cells were grown in Mammary Epithelial Cell Medium (Cambrex) supplemented with $100 \mathrm{ng} / \mathrm{ml}$ cholera toxin. MCF7 cells were grown in Dulbecco's Modified Eagle's Medium supplemented with $10 \%$ fetal bovine serum, 5\% Penicillin Streptomycin Glutamine and 5\% Sodium Pyruvate. Cells were all cultured at $37^{\circ} \mathrm{C}$ in a humidified and $5 \% \mathrm{CO}_{2}$ atomosphere until grown to the desired density in $25 \mathrm{~cm}^{2}$ flasks.

The magnetic iron oxide nanoparticles (maghemite $\gamma$ $\mathrm{Fe}_{2} \mathrm{O}_{3}$ ) in this study were purchased from Alfa Aesar and used without further modification. The average diameter of iron oxide nanoparticle is around $30 \mathrm{~nm}$. Purified CPMVT184C mutant type viral nanoparticles were kindly provided by Dr. Manchester in Scripps Research Institute. Figure 1 shows the Transmission Electron Micrographs of these two nanoparticles. $50 \mu \mathrm{g} / \mathrm{ml}$ iron oxide and CPMV nanoparticles were incubated with MCF7 cancer breast epithelial cells and MCF10A normal breast epithelial cells separately in $25 \mathrm{~cm}^{2}$ flask at $37^{\circ} \mathrm{C}$ in a humidified and $5 \% \mathrm{CO}_{2}$ atomosphere for specified time periods of $30 \mathrm{~min}, 4$ and $24 \mathrm{~h}$. After the incubation procedure, cells were washed with Dulbecco's
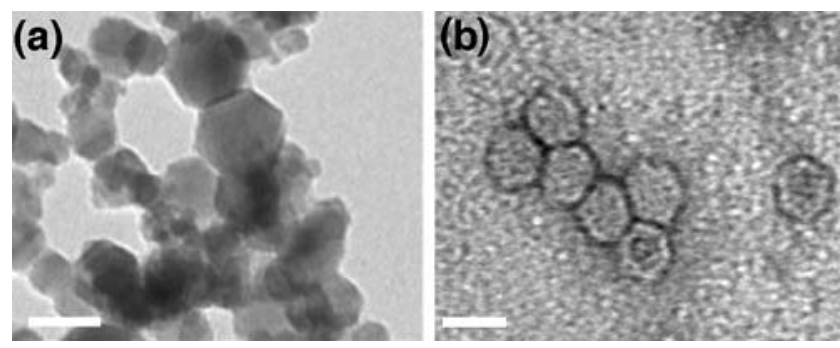

Fig. 1 TEM micrographs of iron oxide nanoparticles (a) and CPMV nanoparticle (b). The length of scale bar is $30 \mathrm{~nm}$ 
Phosphate Buffered Saline (DPBS) for three times. MCF10A cells were lifted off using Typsin-EDTA and MCF 7 cells were lifted off using Cell dissociation buffer (from Invitrogen). After that, they were pelleted down and suspended into Hepes buffer for Zeta potential measurements.

\subsection{Zeta potential measurements}

The Zeta $(\xi)$ potential is the electrostatic potential that exists at the shear plane of a particle, which is related to both surface charge and the local environment of the particle. The Zeta potential of our samples was determined with a Zeta Potential Analyzer from Brookhaven Instruments Corporation. Measurements were recorded at $25^{\circ} \mathrm{C}$ suspended in Hepes buffer (ionic strength $40 \mathrm{mM}$, pH 7.4) with a Ag electrode using Phase Analysis Light Scattering mode. The Zeta $(\xi)$ potential was automatically calculated from electrophoretic mobility based on the Smoluchowski equation, $v=(\varepsilon E / \eta) \xi$, where $v$ is the measured electrophoretic velocity, $\eta$ is the viscosity, $\varepsilon$ is the electrical permittivity of the electrolytic solution and $E$ is the electric field.

\subsection{Transmission electron microscopy (TEM)}

MCF7 and MCF10A cells were cultured on Thermanox plastic cover slips and then incubated with $50 \mu \mathrm{g} / \mathrm{ml}$ iron oxide nanoparticles and CPMV nanoparticles respectively for $30 \mathrm{~min}, 4$ and $24 \mathrm{~h}$. After rinsed with DPBS for three times, the cells were rinsed with $0.1 \mathrm{M}$ Sodium cacodylate, fixed in $2 \%$ Gluteraldahyde in the same buffer, and followed by post fixed with $1 \%$ osmium tetroxode. After dehydrated using an increasing graded ethanol series, the cells were embedded in Spuur resin. Then the specimens were sectioned by a Sorvall MT2 Ultramicrotome and poststained with uranyl acetate and lead citrate. The slides were viewed using a TEM Tecnai12 at Central Facility for Advanced Microscopy and Microanalysis (CFAMM) in the University of California, Riverside. CPMV nanoparticles alone were imaged using TEM Tecnai 12 on plasma oxidized carbon on copper support TEM grids after stained by uranyl acetate.

\section{Theory and analysis}

When nanoparticles are adsorbed at the cell surface they may influence the Zeta potential by (1) influencing the adsorption characteristics of the ions present; (2) shifting the position of the plane of shear from the particle surface. The analysis of this model is given in terms of a parameter $\beta(x)$ which measures how the presence of the nanoparticles affects the free energy of the ions at a distance from the cell surface. The additional free energy is incorporated into the Boltzmann equation (Hunter 1981) so that

$n_{i}(x)=n_{i}^{0} \exp \left[\frac{-z_{i} e \psi}{k T}+\beta(x)\right]$

where $n_{i}$ is the number of ions of type $i$ per unit volume in the double layer region. $n_{i}=n_{i}^{0}$ when $\psi=0 . z_{i}$ is the valence of ion $i . \Psi$ is the potential.

The Poisson-Boltzmann equation (Hunter 1981) is:

$\Delta \psi=\frac{1}{r^{2}} \frac{\mathrm{d}}{\mathrm{d} r}\left(r^{2} \frac{\mathrm{d} \psi}{\mathrm{d} r}\right)=-\frac{1}{\varepsilon} \sum_{i} n_{i} z_{i} e$

For the non adsorption case, $n_{i}(x)=n_{i}^{0} \exp \left(\frac{-z_{i} e \psi}{k T}\right)$, the Poisson-Boltzmann equation in the Debye-Huckel approximation is

$\frac{1}{r^{2}} \frac{\mathrm{d}}{\mathrm{d} r}\left(r^{2} \frac{\mathrm{d} \psi}{\mathrm{d} r}\right)=-\frac{1}{\varepsilon} \sum_{i} n_{i} z_{i} e=\kappa^{2} \psi$

where $\kappa=\left(\frac{e^{2} n_{i}^{0} z_{i}^{2}}{\varepsilon k T}\right)^{1 / 2}, \varepsilon$, is the permittivity.

Solving Eq. 3 and also using the charge balance in the double layer, the potential distribution in the double layer is:

$\psi=\frac{1}{4 \pi \varepsilon_{0}} \cdot \frac{Q}{D(1+\kappa a)} \frac{e^{-\kappa(r-a)}}{r}$

Where $Q$ is cell surface charge, $a$ is the radius of cell.

The potential at the shipping plane surface $r=a+1 / \kappa$ gives the Zeta potential $\zeta$ :

$\zeta=\frac{Q e^{-1}}{4 \pi \varepsilon_{0} D} \cdot \frac{\kappa}{(1+\kappa a)^{2}}$

For cell, the radius $a$ is much larger than the double layer length $1 / \kappa$, the zeta potential can be simplified to:

$\zeta=\frac{Q e^{-1}}{4 \pi \varepsilon_{0} D a^{2}} \cdot \frac{1}{\kappa}$

Substituting Eq. 1 into the Poisson-Boltzmann Eq. 2, we obtain the modified Poisson-Boltzmann equation with nanoparticle adsorption:

$\frac{1}{r^{2}} \frac{\mathrm{d}}{\mathrm{d} r}\left(r^{2} \frac{\mathrm{d} \psi}{\mathrm{d} r}\right)=-\frac{1}{\varepsilon} \sum_{i} n_{i}^{0} z_{i} e \exp \left[\frac{-z_{i} e \psi}{k T}+\beta(x)\right]$

Equation 7 is then solved in the Debye-Huckel approximation with $\beta(x)=\beta$ (a constant). The assumption here is that the nanoparticle is uniformly distributed in the cell interface. 
We get the similar expression of potential distribution and zeta potential is the potential at the shipping plane surface $r=a+1 / \kappa_{\beta}$, where $\kappa_{\beta}=\kappa \exp \left(\frac{-\beta}{2}\right)$ is the modified Debye-Huckel parameter.

$\zeta_{\beta}=\frac{Q e^{-1}}{4 \pi \varepsilon_{0} D a^{2}} \cdot \frac{1}{\kappa_{\beta}}$

The relative zeta potential $Z=\zeta_{\beta} / \zeta_{0}$ comes out to be:

$Z=\exp =\left(\frac{\beta}{2}\right)$

The process of nanoparticle uptake by cells could be considered as composing of two steps: (a) the binding of nanoparticles to the cell surface and (b) the internalization of nanoparticles by specific endocytosis pathway. Here, $\beta$ is positive, i.e. $Z>1$ when nanoparticles bind onto the cell surface with same sign of Zeta potential which increases the free energy of the ions at a distance from the cell surface; $\beta$ is negative, i.e. $Z<1$ during the internalization of nanoparticles by the endocytosis pathway which decreases the surface charge and shift the position of the plane of shear. The relative Zeta potential of cells during the uptake of nanoparticles can be expressed as:

$Z=\exp \left(m_{\text {binding }} \cdot \frac{\beta_{\text {binding }}}{2}-m_{\text {int }} \cdot \frac{\beta_{\text {int }}}{2}\right)$

Where $m_{\text {binding }}$ is the total mass of nanoparticles adsorbed to the cell surface; $m_{\text {int }}$ is the total mass of nanoparticles internalized within the cell. Both the binding and internalization processes can be modeled using Langmuir adsorption (Wilhelm et al. 2002):

$$
\begin{aligned}
\frac{\mathrm{d} m_{\text {int }}(t)}{\mathrm{d} t}= & k_{\mathrm{a}} C\left(m_{0}-m_{\text {binding }}(t)\right)-k_{\mathrm{d}} m_{\text {binding }}(t) \\
& -\frac{\mathrm{d} m_{\text {binding }}(t)}{\mathrm{d} t}
\end{aligned}
$$

$\frac{\mathrm{d} m_{\text {int }}(t)}{\mathrm{d} t}=k_{\mathrm{i}}\left(\phi_{0}-\phi_{\text {int }}(t)\right) m_{\text {binding }}(t)$

$\frac{\mathrm{d} \phi_{\text {int }}(t)}{\mathrm{d} t}=k_{\mathrm{i}}\left(\phi_{0}-\phi_{\text {int }}(t)\right)$

Where $m(t)$ is the mass of nanoparticles which is bound to the cell surface, $C$ is the nanoparticles concentration, $m_{0}$ is the initial nanoparticle mass in the medium, $k_{\mathrm{a}}$ is the adsorption rate, $k_{\mathrm{d}}$ is the desorption rate, $\phi_{\text {int }}$ is the fraction of the reactive surface being internalized, $\phi_{0}$ is the maximum fraction of reactive surfaces, and $k_{\mathrm{i}}$ is the internalization constant. The set of differential equations (11-13) can be solved numerically.

Figure 2 illustrates the theoretical evaluation of Zeta potential change with time under the effect of binding and internalization processes. When the binding effect dominates the whole uptake process, the Zeta potential increases with the time until it reaches the saturation region (Fig. 2 (a)).When the internalization effect plays the most important role during the uptake, the Zeta potential decreases with time (Fig. 2 (b)). It has been reported that the endocytosis capacity is pretty cell specific (Wilhelm et al. 2002). The cancer cells have comparatively a reduced endocytosis capacity. So naturally, it is expected that the Zeta potential for normal cells and cancer cells will have different trends during the nanoparticles uptake process.

(a)

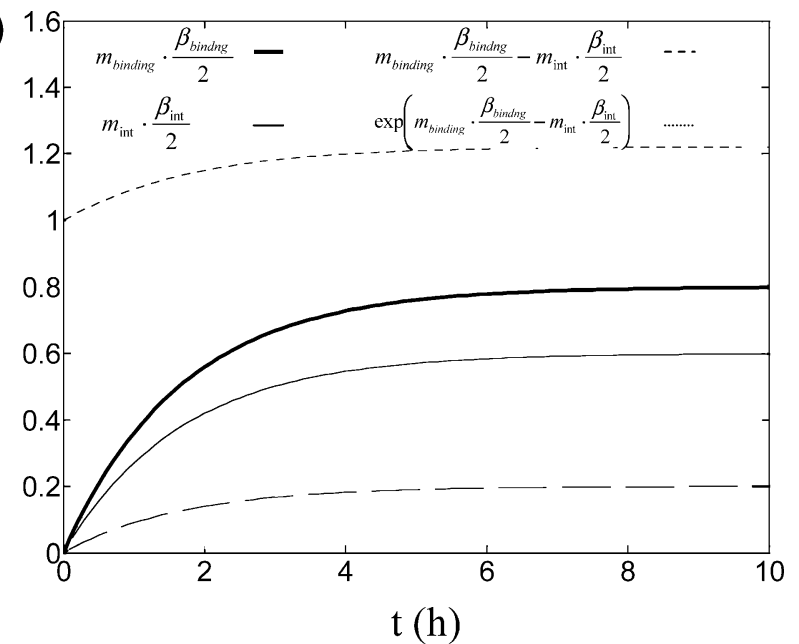

(b)

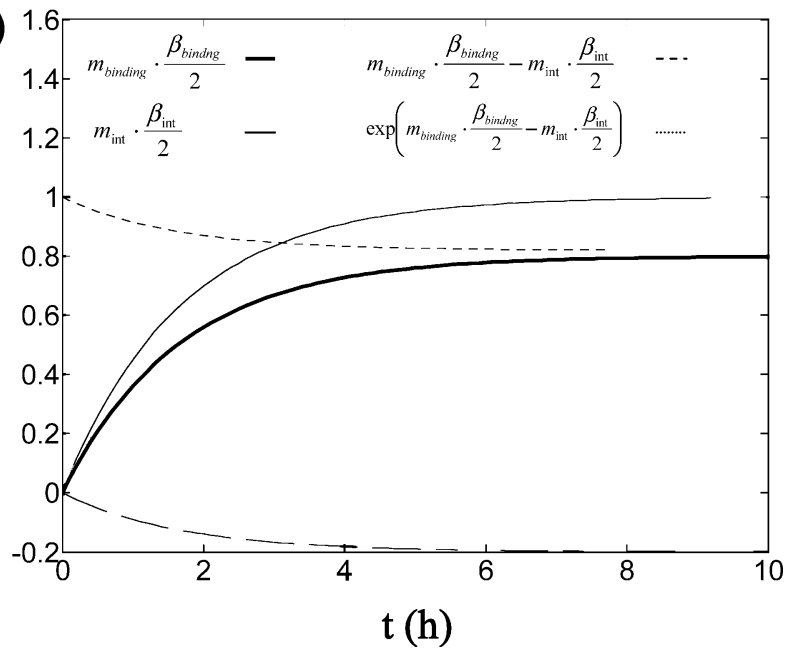

Fig. 2 Theoretical evaluation of Zeta potential vs. time for different nanoparticles adsorption process: (a) the binding effect is larger than internalization effect; (b) the binding effect is smaller than internalization effect 


\section{Results and discussion}

Figure 3 shows the experimental results of Zeta potential measurements at $\mathrm{pH} 7.4$ for MCF7 cancer breast epithelial cells alone, MCF10A normal breast epithelial cells alone, iron oxide nanoparticles alone, CPMV nanoparticles alone as well as two types of cells after incubated with two different nanoparticles respectively for different time lengths of $30 \mathrm{~min}, 4$ and $24 \mathrm{~h}$. For MCF10A normal cells alone, the Zeta potential was $-31.16 \pm 1.12 \mathrm{mV}$, which was much more negative compared to that of $-20.32 \pm 2.43 \mathrm{mV}$ for MCF7 cancer cells. This significant difference in surface electrokinetic properties between normal and transformed cancer cells has been reported before (Cook and Jacobson 1968). For iron oxide nanoparticles alone, the Zeta potential was $-40.91 \pm 0.14 \mathrm{mV}$ indicating good dispersion stability. For CPMV nanoparticles alone, the Zeta potential was $-13.45 \pm 2.81 \mathrm{mV}$, which is within the range of dielectric properties of CPMV reported by Ermolina et al. (2006). The results of Zeta potential measurements of MCF7 and MCF10A cells after incubated with two different kinds of nanoparticles are very interesting. Figure 3(a) shows the Zeta potential value of MCF10A cells after incubated with iron oxide nanoparticles slightly increased from $-31.16 \pm 1.12 \mathrm{mV}$ to $-30.47 \pm$
$0.15 \mathrm{mV}$ after $30 \mathrm{~min}$ of incubation. This trend continued as the Zeta potential value became $-28.05 \pm 0.91 \mathrm{mV}$ after $4 \mathrm{~h}$ incubation and $-27.05 \mathrm{mV} \pm 0.47 \mathrm{mV}$ after $24 \mathrm{~h}$ of incubation. Figure 3(b) shows that for MCF7 cells, the Zeta potential value changed in the opposite way after they were incubated with iron oxide nanoparticles. The Zeta potential value dropped significantly from $-20.32 \pm$ $2.43 \mathrm{mV}$ to $-25.17 \pm 0.52 \mathrm{mV}$ after the first $30 \mathrm{~min}$ of incubation and became $-24.63 \pm 0.67 \mathrm{mV}$ after $4 \mathrm{~h}$ of incubation and further dropped to $-26.55 \pm 0.78 \mathrm{mV}$ after $24 \mathrm{~h}$ of incubation. The Zeta potential values after incubation with iron oxide nanoparticles turned out to change in opposite ways for cancer cells (MCF7) compared to normal cells (MCF10A). In the case of CPMV nanoparticles, Fig. 3(c) shows that the change of Zeta potential values of MCF10A cells after incubated with CPMV nanoparticles also increased slightly from $-31.16 \pm$ $1.12 \mathrm{mV}$ to $-29.93 \pm 0.88 \mathrm{mV}$ after $30 \mathrm{~min}$ of incubation, and kept this tendency to $-29.31 \pm 0.28 \mathrm{mV}$ after $4 \mathrm{~h}$ incubation and to $-25.49 \mathrm{mV} \pm 2.11 \mathrm{mV}$ after $24 \mathrm{~h}$ of incubation. For MCF7 cells, Fig. 3(d) shows that the Zeta potential value again changed in contrary to MCF10A cells after they were incubated with CPMV nanoparticles. The Zeta potential value dropped significantly from $-20.32 \pm$ $2.43 \mathrm{mV}$ to $-24.51 \pm 0.73 \mathrm{mV}$ after the first $30 \mathrm{~min}$, became
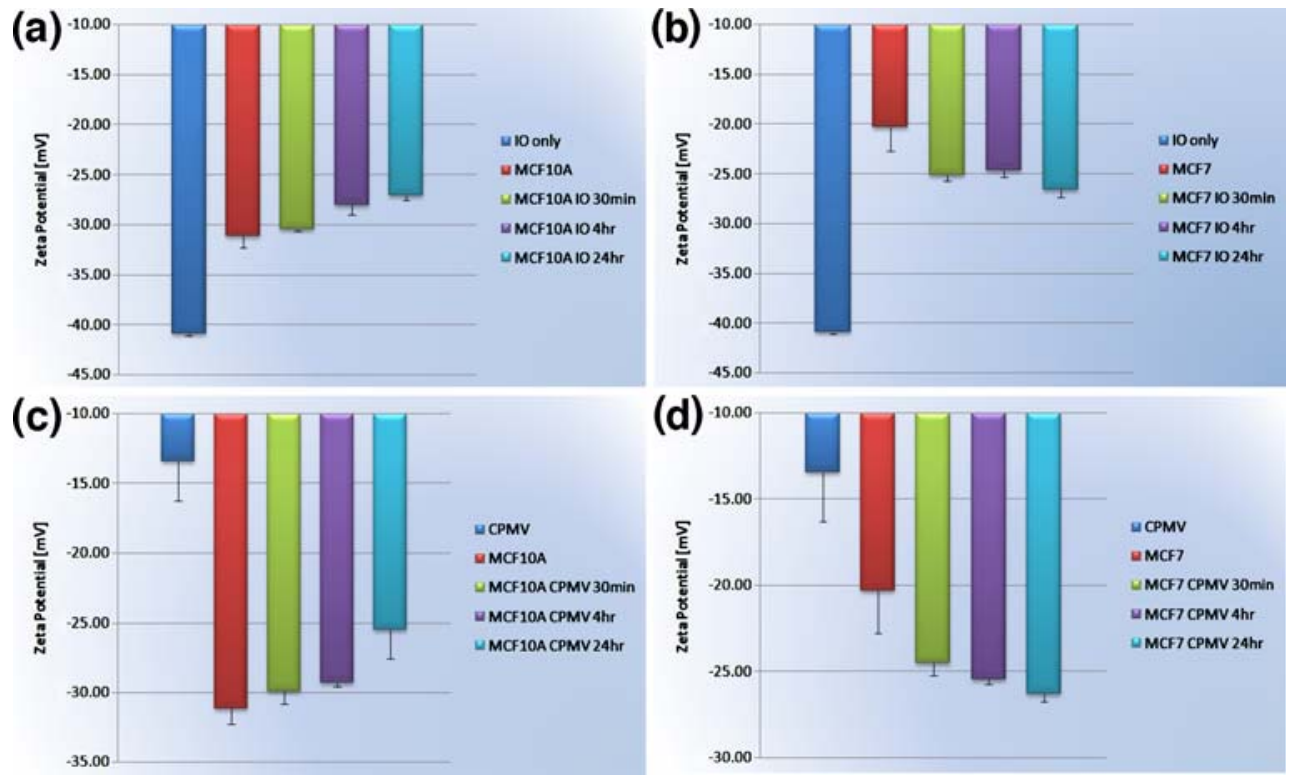

Fig. 3 These bar graphs show the results of Zeta Potential measurements for normal breast epithelial cell (MCF10A), cancer breast epithelial cell (MCF7), iron oxide nanoparticles, CPMV nanoparticles, as well as the changes in the zeta potential values of cells after incubated with these two types of nanoparticles. All the zeta potential were measured using a ZetaPALS system in Hepes buffer (ionic strength $40 \mathrm{mM}, \mathrm{pH}$ 7.4). (a) Comparison of Zeta Potential values of iron oxide nanoparticles alone, MCF10A cells alone, and MCF10A cells after incubated with iron oxide nanoparticles for $30 \mathrm{~min}, 4$ and $24 \mathrm{~h}$ at $37^{\circ} \mathrm{C}$; (b) Comparison of Zeta Potential values of iron oxide

nanoparticles alone, MCF7 cells alone and MCF7 cells after incubated with iron oxide nanoparticles for $30 \mathrm{~min}, 4$ and $24 \mathrm{~h}$ at $37^{\circ} \mathrm{C}$; (c) Comparison of zeta potential values of CPMV nanoparticles alone, MCF10A cells alone and MCF10A cells after incubated with CPMV nanoparticles for $30 \mathrm{~min}, 4$ and $24 \mathrm{~h}$; (d) Comparison of zeta potential values of CPMV nanoparticles alone, MCF7 cells alone, and MCF7 cells after incubated with CPMV nanoparticles for $30 \mathrm{~min}, 4$ and $24 \mathrm{~h}$. Note: On the bar graph, IO stands for iron oxide nanoparticles and the error bar indicates the standard error for 8 runs of Zeta Potential measurements 
$-25.44 \pm 0.31 \mathrm{mV}$ after $4 \mathrm{~h}$ and further dropped to $-26.29 \pm$ $0.46 \mathrm{mV}$ after $24 \mathrm{~h}$. In summary, the Zeta potential change differences between MCF7 cells and MCF10A cells are distinct after incubated with nanoparticles. However, similar patterns occurred for the same type of cell after incubated with two different nanoparticles.

As we mentioned before, the nanoparticle uptake by cells could be considered as a binding process followed by an internalization process. The possible mechanism for the opposite trends of Zeta potential change between normal cells and cancer cells could be explained by the following reasons. First, the binding of charged nanoparticles to the cell surface plasma membrane will change the Zeta potential value of the cells. Zeta potential has been used to diagnose the cellular interaction with charged ions or molecules and the results showed that negatively charged ions or molecules will decrease the surface Zeta potential and positively charged ions will increase the surface Zeta potential (Altankov et al. 2003; Siliva Filho et al. 1987). As the Zeta potential value of nanoparticles we used in this study were all negative, attachment of anionic nanoparticles on the cell plasma membrane will cause the Zeta potential to become intuitively more negative. The internalization process resulting in the change of Zeta potential may be due to the vesicular transport based cell endocytosis. During endocytosis, cells uptake external substances by invaginating a small portion of the surface plasma membrane to form a new intracellular vesicle around the substance to transport inside the cells (Cooper 2000). Since the cell membrane is overall negatively charged (Coleman and Finean 1968), the loss of negatively charged cell membrane during vesicular transport and negatively charged nanoparticles loaded inside the vesicles will cause the Zeta potential values to become intuitively less negative.

Figure 4 shows Transmission Electron Micrographs of MCF7 and MCF10A cells after incubated with iron oxide nanoparticles for different time lengths and these images verified that both cells internalized iron oxide nanoparticles through vesicular transport. Figure 4(a) shows that after 30 min incubation with MCF10A cells, a vesicle loaded with iron oxide nanoparticles just formed. Multiple vesicles containing iron oxide nanoparticles were observed within the cell cytoplasm in Fig. 4(b) after $4 \mathrm{~h}$ and Fig. 4(c) after $24 \mathrm{~h}$. For MCF7 cells, they might have a slower uptake compared to MCF10A cells. Figure 4(d) and (e) show that iron oxide nanoparticles still bind on the cell surface after $30 \mathrm{~min}$ and $4 \mathrm{~h}$, which might be the reason why the Zeta potential of MCF7 cells dropped significantly compared to MCF10A cells. Figure 4 (f) shows that multiple vesicles were also formed within the MCF7 cell cytoplasm after $24 \mathrm{~h}$. From the images we got, the average size of the vesicles formed in MCF7 cells is bigger than that of MCF10A cells, as well as the number of iron oxide nanoparticles inside each vesicle are much more than that of MCF10A cells. These indicate the specific cell functionality between normal and cancer breast cells. Nanoparticles didn't enter mitochondria or cell nucleus from the TEM images we got. Figure 5(a) and (b) show the Transmission Electron Micrographs of MCF10A cells and MCF7 cells after incubated with CPMV nanoparticles for $24 \mathrm{~h}$ respectively. From these two images, we observed huge vesicles were formed in both type of cells. For MCF10A cells (Fig. 5(a)), the vesicle was filled with basically clustered CPMV nanoparticles whereas fractured CPMV nanopar-
Fig. 4 Transmission Electron Micrographs of MCF10A cells that were incubated with iron oxide nanoparticles for $30 \mathrm{~min}$ (a), $4 \mathrm{~h} \mathrm{(b)} \mathrm{and} 24 \mathrm{~h} \mathrm{(c)} \mathrm{at} 37^{\circ} \mathrm{C}$. Transmission Electron Micrographs of MCF7 cells that were incubated with iron oxide nanoparticles for $30 \mathrm{~min}(\mathrm{~d}), 4 \mathrm{~h}$ (e) and $24 \mathrm{~h}(\mathrm{f})$ at $37^{\circ} \mathrm{C}$. All slices were treated with uranyl acetate to stain membranes and lead citrate to stain the nuclear body. Colored arrows represent selected cell organelles: nuclei (yellow), neucleolus (green), mitochondria (blue), and vesicles with iron oxide nanoparticles inside (red), filaments (purple)
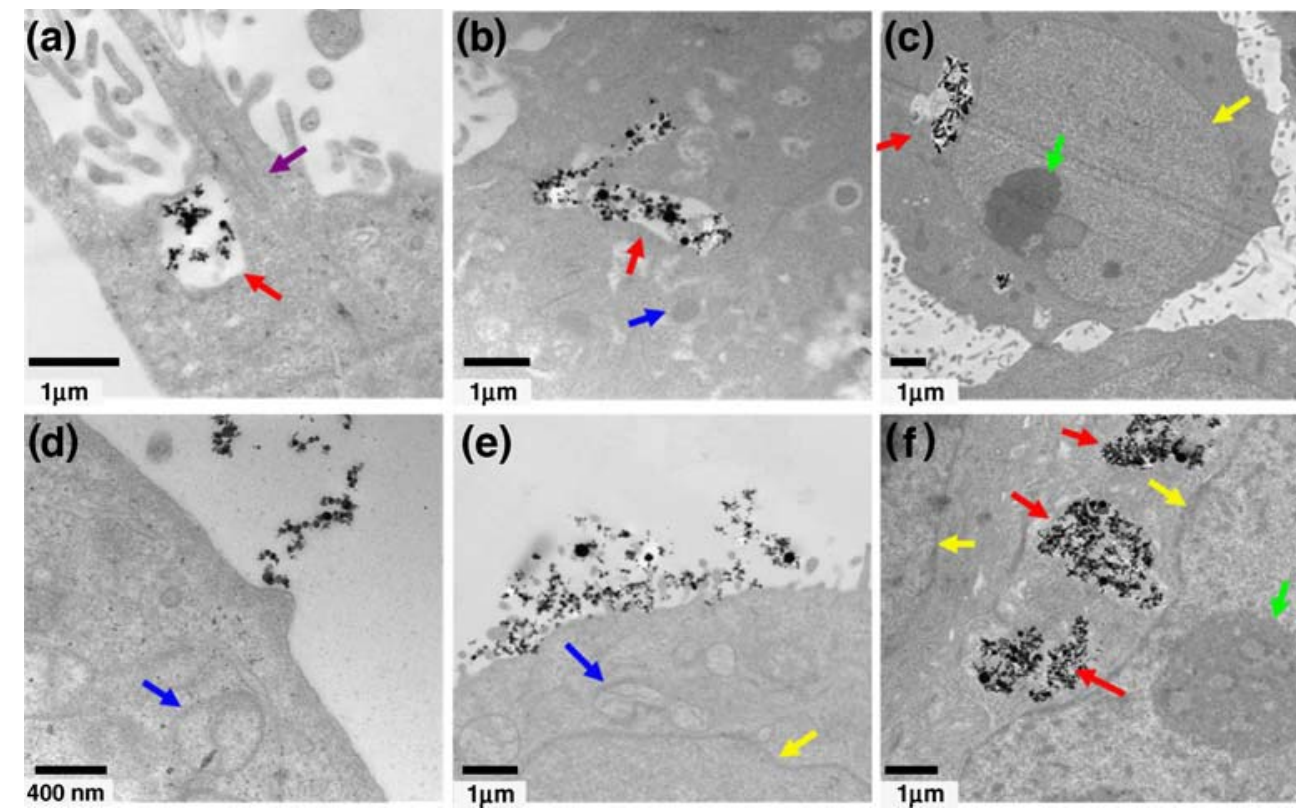


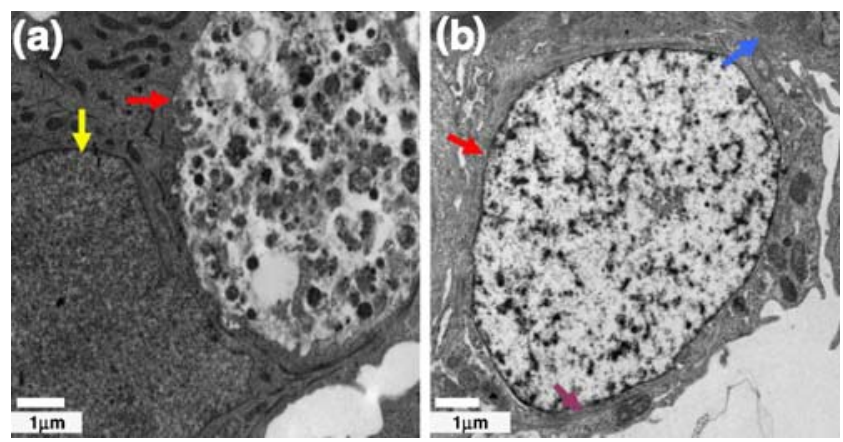

Fig. 5 (a) Transmission Electron Micrographs of MCF10A cells that were incubated with CPMV-T184C nanoparticles for $24 \mathrm{~h}$ at $37^{\circ} \mathrm{C}$. * (b) Transmission Electron Micrographs of MCF7 cells that were incubated with CPMV nanoparticles for $24 \mathrm{~h}$ at $37^{\circ} \mathrm{C}$. Colored arrows represent selected cell organelles: nuclei (yellow), vesicles with CPMV nanoparticle clusters and fragments inside (red), mitochondria (blue), and filaments (purple)

ticles filled the vesicle inside MCF7 cells (Fig. 5(b)). This fact also indicates the specific cell functionality between normal and cancer breast cells.

Since iron oxide nanoparticles and CPMV nanoparticles are all negatively charged on the surface, electrostatic repulsion between anionic nanoparticles and negatively charged cell membrane should repel the uptake of nanoparticles. As we have observed nanoparticle endocytosis from the TEM images, the uptake of iron oxide nanoparticles and CPMV nanoparticles by cells could be mediated by certain proteins despite their negative surface charge. Nonspecific adsorption of proteins on the iron oxide nanoparticle surface from cell culture medium will induce the uptake of nanoparticles via receptor-mediated cell endocytosis like other oxide and metal nanoparticles did (Limbach et al. 2005; Wilhelm et al. 2002; Chithrani et al. 2006). The agglomeration of iron oxide nanoparticles after incubated with cells that we observed in TEM images may also be caused by smaller surface charge after protein adsorption and the repulsive forces by negatively charged cell surface. The uptake mechanism of CPMV nanoparticle by human cells is little known, but a recent study of CPMV have identified a mediated endocytosis of CPMV via a $54 \mathrm{kD}$ protein found on the plasma membrane of both human and muring cell lines (Koudelka et al. 2007).

Figure 6 reveals the changes of Zeta potential values with theoretical fittings for MCF10A normal cells and MCF7 cancer cells after incubated with iron oxide and CPMV nanopaticles. In general, the Zeta potential of MCF7 cells decreased after incubated with these two kinds of nanoparticles compared to the increase of Zeta potential of MCF10A cells. The Zeta potential of MCF7 cells became more negative after incubated with nanoparticles, which might be due to the dominant binding effect of nanoparticles on the cell surface membrane. This is consistent with the significant drop of Zeta potential value of MCF7 cells after the first $30 \mathrm{~min}$ of incubation. The accumulation of nanoparticles for longer time periods over the cell surface and slower endocytosis observed in MCF7 cancer cells experiments may suggest that the effect of nanoparticle binding was more dominant compared to internalization process, which including the loss of negatively charged plasma membrane of MCF7 cells and anionic
Fig. 6 Zeta potential change with theoretical fitting for MCF10A cells and MCF7 cells after incubated with iron oxide and CPMV nanopaticles for $30 \mathrm{~min}, 4$ and $24 \mathrm{~h}$. The zeta potential of MCF7 cells decreased after incubated with nanoparticles in contrary to a trend of increase for MCF10A cells after incubated with nanoparticles. The $x$ axis for time length used a logarithm scale

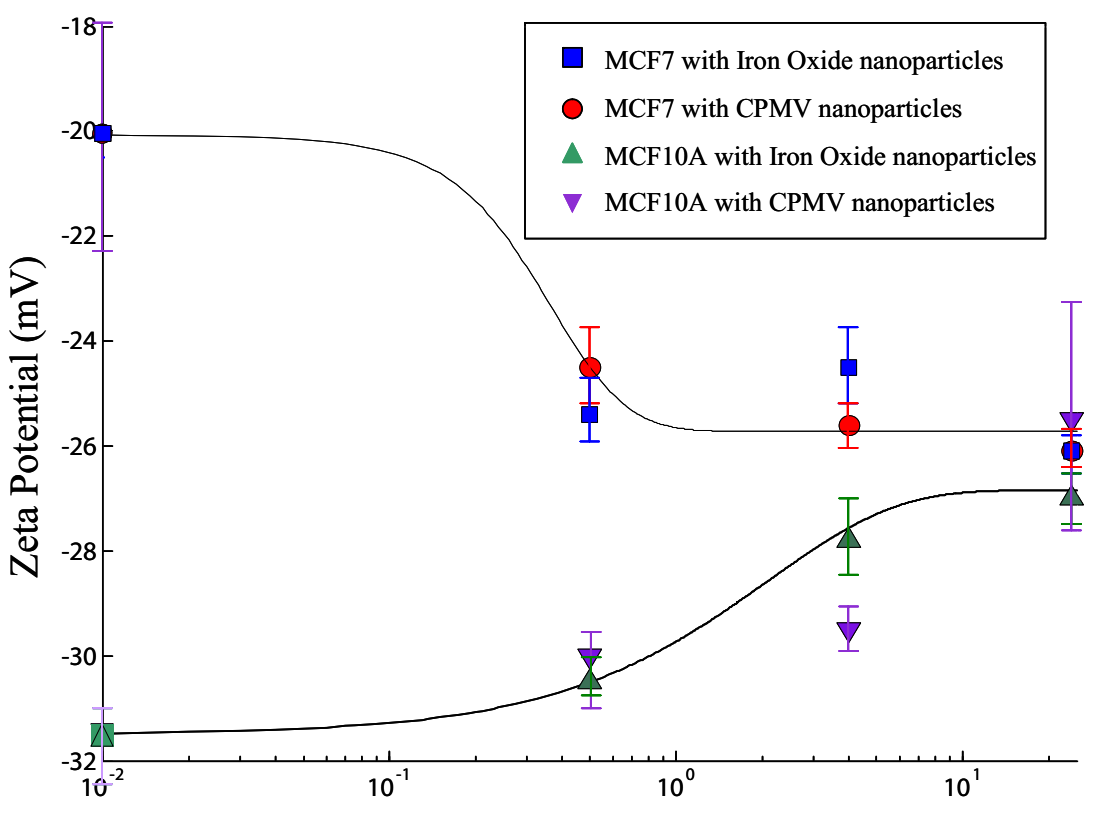

$\mathrm{t}(\mathrm{h})$ 
nanoparticles after endocytosis. However, for MCF10A cells, nanoparticles were more actively internalized, hence the internalization effect may dominate and finally cause the zeta potential to increase. The surface charge of cells over time is affected by the whole nanoparticle uptake process and which is reflected in the changes of zeta potential values after incubated with nanoparticles for different time lengths.

From Fig. 6, similar patterns are observed for the same type of cell after incubated with two different nanoparticles. For oxide nanoparticles, protein adsorption will significantly affect surface charge and shift the zeta potential to a much smaller negative value after mixed with cell culture medium (Limbach et al. 2005). Although iron oxide nanoparticles alone has a much lower Zeta potential value of $-40.91 \pm 0.14 \mathrm{mV}$ compared to $-13.45 \pm 2.81 \mathrm{mV}$ of CPMV nanopaticles alone, after incubated with cells, iron oxide nanoparticles should have adsorpted proteins on their surfaces and their surface charge became close to CPMV nanopaticles. That may be the reason that the Zeta potential value change is similar instead of a big difference for two different nanoparticles.

\section{Conclusions}

In conclusion, the Zeta potential change of cells after incubated with nanoparticles is determined by a combination of binding effect and internalization effect to the overall nanoparticles uptake process. The surface charge of cells, the surface charge of nanoparticles and the interaction between cells and nanoparticles led to distinct patterns in Zeta potential measurements between normal breast cells (MCF10A) and cancer breast cells (MCF7). This indicate that Zeta potential may not only provide an insight into the nature of the cellular interaction with nanoparticles, but also can be utilized as a more streamlined method for probing the nature of specific normal and cancer cells responses with potential nanoparticle-based methods of diagnosis and therapeutics. This is the first attempt to use Zeta potential measurements as a cellular signature to study surface interaction and cellular uptake of nanoparticles.

Acknowledgements Funding for this project provided by the Center of Excellence of Nanotechnology for Treatment, Understanding, and Monitoring of Cancer (NANO-TUMOR) has been gratefully acknowledged. We thank Dr. Maria Jose of the Moores Cancer Center at UC, San Diego (UCSD) for technical assistance in cell culture and $\mathrm{Mr}$. Stephen McDaniel for preparing microtome cell slides for transmission electron microscopy. We also thank Dr. Sadik Esener and Michael Heller of UCSD for helpful discussions on cell surface charge.

\section{References}

C. Alexiou, W. Arnold, R.J. Klein, F.G. Parak, P. Hulin, C. Bergemann, W. Erhardt, S. Wagenpfeil, A.S. Lubbe, Cancer Res 60, 6641-6648 (2000)

G. Altankov, K. Richau, T. Groth, Mater.wiss. Werkst.tech 34, 1120 1128 (2003)

L. Babes, B. Denizot, G. Tanguy, J. Le, J. Jean, P. Jallet, J. Colloid Interface Sci 212, 474-482 (1999)

C.C. Berry, A.S. Curtis, J. Phys., D, Appl. Phys 36, R198-R206 (2003)

A.S. Blum, C.M. Soto, C.D. Wilson, J.D. Cole, M. Kim, B. Gnade, A. Chatterji, W.F. Ochoa, T.J. Lin, J.E. Johnson, B.R. Ratna, Nano Lett 4, 867-870 (2004)

B.D. Chithrani, A.A. Ghazani, W.C.W. Chan, Nano Lett 6, 662-668 (2006)

R. Coleman, J.B. Finean, Comp. Biochem 23, 99-126 (1968)

G.M.W. Cook, W. Jacobson, Biochem. J 107, 549-557 (1968)

G.M. Cooper, The Cell: a Molecular Approach, 2nd edn. (ASM Press, Washington D.C, 2000)

A. Dyal, K. Loos, M. Noto, S.W. Chang, C. Spagnoli, K.V. Shafi, A. Ulman, M. Cowman, R.A. Gross, J. Am. Chem. Soc 125, 16841685 (2003)

I. Ermolina, J. Milner, H. Morgan, Electrophoresis 27, 3939-3948 (2006)

A. Fontes, H.P. Fernandes, M.L. Barjas Castro, A.A. de Thomaz, L.Y. Pozzo, L.C. Barbosa, C.L. Cesar, Microsc. Microanal 12, 17581759 (2006)

A.K. Gupta, M. Gupta, Biomaterials 26, 3995-4021 (2005)

A.K. Gupta, S. Wells, IEEE Trans. Nanobiosci 3, 66-73 (2004)

R. Hergt, W. Andra, C.G. d'Ambly, I. Hilger, W.A. Kaiser, U. Richter, H. Schmidt, IEEE Trans. Magn 34, 3745-3754 (1998)

R.J. Hunter, Zeta Potential in Colloid Science Principles and Applications (Academic Press Inc, 1981)

T.K. Jain, M.A. Morales, S.K. Sahoo, D.L. Leslie-Pelecky, V. Labhasetwar, Mol. Pharmacol 2, 194-205 (2005)

K.J. Koudelka, C.S. Rae, M.J. Gonzalez, M. Manchester, J Virol 81, 1632-1640 (2007)

H. Lee, E. Lee, D.K. Kim, N.K. Jang, Y.Y. Jeong, S. Jon, J. Am. Chem. Soc 128, 7383-7389 (2006)

J.D. Lewis, G. Destito, A. Zijlstra, M. Gonzalez, J. Quigley, M. Manchester, H. Stuhlmann, Nat. Med 12, 354-360 (2006)

L.K. Limbach, Y. Li, R.N. Grass, T.J. Brunner, M.A. Hintermann, M. Muller, D. Gunther, W.J. Stark, Environ. Sci. Technol 39, 93709376 (2005)

D. Lin, L. Zhong, S. Yao, Biotechnol. Bioeng 95, 185-191 (2006)

G.P. Lomonossoff, W.D.O. Hamilton, Curr. Top. Microbiol. Immunol 240, 177-189 (1999)

M. Manchester, P. Singh, Adv. Drug Deliv. Rev 58, 1505-1522 (2006)

H. Pardoe, P.R. Clark, T.G. St Pierre, P. Moroz, S.K. Jones, Magn. Reson. Imaging 21, 483-488 (2003)

J.M. Perez, T. O'Loughin, F.J. Simeone, R. Weissleder, L. Josephson, J. Am. Chem. Soc 124, 2856-2857 (2002)

F.C. Siliva Filho, A.B. Santos, T.M. de Carvalho, W. de Souza, J. Leukoc. Biol 41, 143-149 (1987)

F. Sonvico, S. Mornet, S. Vasseur, C. Dubernet, D. Jaillard, J. Degrouard, J. Hoebeke, E. Duguet, P. Colombo, P. Couvreur, Bioconjug. Chem 16, 1181-1188 (2005)

B. Veronesi, H. Colin, L. Lee, M. Oortgiesen, Toxicol. Appl. Pharmacol 178, 144-154 (2002)

C. Wilhelm, F. Gazeau, J. Roger, J.N. Pons, J.-C. Bacri, Langmuir 18, 8148-8155 (2002) 